\title{
SYNTHETIC DESIGN AND INVESTIGATION OF NOVEL POLYMERIC SURFACTANTS
}

\author{
Garrett F. Bass, Mark S. Colt, Anton D. Chavez, Guilhem X. DeHoe, Thaddeus P. \\ Formal, Craig P. Seaver, Kimberly Kha, Brett A. Kelley, Gregory E. Scott, Chad E. \\ Immoos and Philip J. Costanzo* \\ Department of Chemistry and Biochemistry, California Polytechnic State University, \\ California
}

AUTHOR EMAIL ADDRESS : pcostanz@calpoly.edu

CORRESPONDING AUTHOR FOOTNOTE : Correspondence should be addressed to Philip J. Costanzo, California Polytechnic State University, Department of Chemistry and Biochemistry. San Luis Obispo, CA 93407-0402

KEYWORDS: RAFT; carbon nanotubes; polymeric surfactants; block copolymers 


\section{ABSTRACT.}

A library of polymeric amphiphiles was prepared based on a one-pot methodology using reversible addition fragmentation chain transfer (RAFT) polymerization. These surfactants where then employed to disperse carbon nanotubes (CNTs) within water and an aqueous DMSO solution. All polymeric materials that were soluble in water were used to prepare dispersions of CNT. A range of experimental techniques including atomic force microscopy (AFM), fluorescence quenching experiments, UV/Vis absorbance measurements and ${ }^{1} \mathrm{H}$ NOESY NMR spectroscopy were employed to probe the interactions between the CNT and the polymeric surfactant.

\section{Introduction}

A fundamental understanding of how to optimize surfactant efficiency with simple and efficient synthetic methods is sought after for a variety of applications, including aqueous-based, conductive spray coatings. We chose carbon nanotubes (CNTs) as a potential additive due to their high Young's modulus and conductivity. ${ }^{1,2}$ Unfortunately CNTs display extremely poor dispersibility in aqueous media due to very strong van der Waals forces caused by strong $\pi-\pi$ interactions between the CNTs leading to aggregation.

There are two main methods to improve CNT dispersibility. The first is covalent chemical modification of the CNT sidewall to introduce solubilizing groups. While this is effective in aiding dispersion, the $\mathrm{sp}^{2}$ network of carbon atoms is disrupted, reducing the strength and conductivity of the material. A second approach employs a surfactant molecule that is able to interact with the CNT through non-covalent interactions that preserves the CNT structure while increasing the dispersibility of the CNT. ${ }^{3-5}$

Typical ionic surfactant molecules are amphiphilic, consisting of a hydrophilic head (commonly an acidic functional group) and a hydrophobic tail (commonly an aliphatic chain). Sodium dodecyl sulfate (SDS) is one of the most common small molecule surfactants. One may also employ non-ionic surfactants such as Igepal products, where the hydrophilic portion is replaced with a segment of poly(ethylene glycol) (PEG), and the hydrophobic portion can be an alkyl chain. Variation in the length of the hydrophobic and hydrophilic subunits distinguishes the various commercially available Igepal products.

These surfactant molecules can self-assemble into various solution-state structures including micelles and vesicles. One can control the solution structure by tailoring the relative sizes of the hydrophilic and hydrophobic segments. Various research groups have synthesized a wide range of small molecule surfactants with variation in the hydrophilic and hydrophobic segments to alter the critical micelle concentration, which is the minimum concentration needed for solution-state structures to form.

With the development of controlled radical polymerization techniques such as atom transfer radical polymerization $(\mathrm{ATRP})^{6,7}$, reversible addition fragmentation chaintransfer $(\mathrm{RAFT})^{8}$ and nitroxide-mediated polymerization $(\mathrm{NMP})^{9}$, there have been 
significant advances in the synthetic design and preparation of novel polymeric materials. ${ }^{10,11}$ In particular, polymeric surfactants have been synthesized by multiple groups to yield novel solution-state structures including micelles, vesicles and toroids by employing different polymer compositions and basic surfactant principles. ${ }^{12-20}$

There are multiple reports of the preparation of amphiphilic block copolymers that contain a poly(styrene) (PS) block and a poly(t-butyl acrylate) (PtBA) block, where a hydrophilic segment can be generated by treatment with trifluoroacetic acid to yield a poly(acrylic acid) block (PAA). ${ }^{12,15,16}$ We hypothesized that the hydrophobic PS block would interact with the CNT via $\pi-\pi$ stacking and the hydrophilic PAA would improve CNT dispersion in aqueous solutions. While our initial synthetic routes employed ATRP and NMP polymerization techniques, work by Sumerlin et al. demonstrated the preparation of block copolymer amphiphiles in a simple one-step process that were able to self-assemble into solution-state structures. ${ }^{21}$ Here, a block copolymer of poly(St-altMAn)-block-poly(St) was prepared followed by treatment under acidic conditions resulting in a poly(St-alt-MA)-block-poly(St). Employing that previously developed methodology, we were able to easily synthesize a library of polymeric surfactants with hydrophobic styrenic units that can complex with the CNTs, while allowing the hydrophilic units to impart aqueous solubility and improve dispersion stability. We hope to exploit the preparation of pre-determined synthetic targets to develop a better understanding of block composition in the development of polymeric surfactants.

\section{Experimental}

\subsection{Materials}

All materials were purchased from commercially available sources. Styrene (St) was dried over $\mathrm{CaH}_{2}$ and distilled to remove inhibitor. Maleic anhydride (MAn) was recrystallized from toluene. The chain transfer agent (CTA), 2-(2Carboxyethylsulfanylthiocarbonylsulfanyl) propionic acid was synthesized according to previously reported methods. ${ }^{22}$ Nanopure $\mathrm{H}_{2} \mathrm{O}$ was employed for all absorption and emission experiments. Single/multi-walled carbon nanotubes were generously donated by Dr. Greg O'Bryan from Sandia National Laboratories.

\subsection{Experimental}

2.2.1 Typical RAFT polymerization for preparation of poly(St-alt-MAn)-block-poly(St) copolymer

A stirbar, St, MAn, CTA, AIBN and toluene were loaded into a round bottom flask. An initial sample was removed and the flask was sealed with a rubber septum and purged with $\mathrm{N}_{2}$ for at least $30 \mathrm{~min}$. The reaction mixture was placed into a temperature controlled oil bath for a specified time. A final sample was removed for determination of conversion via NMR spectroscopy. The reaction mixture was diluted with acetone and then precipitated into $\mathrm{MeOH}$ to yield the desired poly(St-alt-MA)-block-poly(St) 
copolymer as a yellow powder. Typical yields ranged from $50-80 \%$. Please refer to Table 1 for a list of reaction conditions, conversion and molecular weight data.

2.2.2 Typical hydrolysis reaction to prepare poly(St-alt-MA)-block-poly(St) copolymer

A stirbar, poly(St-alt-MAn)-block-poly(St) copolymer and acetone were loaded into a round bottom flask. Next, conc. $\mathrm{H}_{2} \mathrm{SO}_{4}$ was added until precipitation began to occur followed by a minimal amount of acetone to restore clarity to the solution. The reaction mixture was then stirred at $45^{\circ} \mathrm{C}$ overnight. The reaction mixture was precipitated into hexanes to yield an off-white powder. Typical yields ranged from $50-80 \%$.

\subsection{Instrumentation}

\subsubsection{General characterization}

${ }^{1} \mathrm{H}$ NMR spectra were recorded on a $400 \mathrm{MHz}$ Varian instrument. Chemical shifts, $\delta$ (ppm), were referenced to the residual solvent signal. IR analysis was conducted on a Nicolet iS10 FT-IR spectrometer utilizing an ATR attachment. GPC analysis was conducted in THF at $25{ }^{\circ} \mathrm{C}$ with flow rate of $1.00 \mathrm{ml} \mathrm{min}^{-1}$. Three Polymer Standards Service columns (100 $\AA, 1000 \AA$ and linear) were connected in series to a Thermoseparation Products P-100 isocratic pump, autosampler, column oven, and Knauer refractive index detector.

\subsubsection{Determination of Critical Micelle Concentration (CMC)}

Varying amounts of polymer (loadings from $0.1 \mathrm{mg} / \mathrm{mL}$ to $5 \mathrm{mg} / \mathrm{mL}$ ) were added to solutions containing Rhodamine-6G (5 $\mu \mathrm{M}$ ) and triethyl amine (a molar equivalency to $\mathrm{COOH}$ groups present). Absorbance measurements at $534 \mathrm{~nm}$ where monitored employing an Ocean Optics USB 2000 instrument.

\subsubsection{Fluorescence}

Various solution combinations of Rhodamine 6G $(2.5 \mu \mathrm{M})$, CNTs $(16 \mu \mathrm{g} / \mathrm{mL})$, and polymer $(2.5 \mathrm{mg} / \mathrm{mL})$ were prepared in $\mathrm{H}_{2} \mathrm{O}$, and emission spectra were observed when employing an excitation wavelength of $500 \mathrm{~nm}$ on a JASCO FP-6500 Spectrofluorometer.

\subsubsection{UV-Visible absportion}

Various solution combinations of Reichardt's dye $(218.9 \mu \mathrm{M})$, CNTs $(10 \mu \mathrm{g} / \mathrm{mL})$, and polymer $(2.5 \mathrm{mg} / \mathrm{mL}$ with triethylamine in a molar equivalency to $\mathrm{COOH}$ groups present) were prepared in 60:40 DMSO: $\mathrm{H}_{2} \mathrm{O}$, and absorption spectra were observed on a Jasco V-550 UV-Visible spectrophotometer at $25^{\circ} \mathrm{C}$. For samples containing CNT's, solutions were sonicated for 10 minutes and shaken vigorously $(\times 3)$ during sonication to ensure dispersion of CNT. 


\subsubsection{AFM analysis}

Various solutions of CNTs with polymer in 60:40 DMSO: $\mathrm{H}_{2} \mathrm{O}$ were dispersed onto silicon surfaces by aerosol deposition with an Iwata CM-SB airbrush, drying gently with air between each layer deposited. To prepare a sample with unwrapped CNTs, polymer solutions were deposited first and CNTs were sonicated in dichloroethane, centrifuged, and the supernatant with dispersed CNTs was deposited by aerosol deposition. Noncontact AFM micrographs were obtained using an Asylum Research MFP-3D and a Park XE-70.

\section{Results and Discussion}

Scheme 1 displays the synthetic route employed to prepare block copolymers in a onepot method. The reactivity ratios between styrene and MAn, 0.05 and 0.005, respectively, ${ }^{23}$ result in the preparation of an alternating copolymer. By employing an excess of styrene, after the consumption of MAn, a continuous block of styrene will be form resulting in a block copolymer of poly(St-alt-MAn)-block-poly(St). ${ }^{21,24} \mathrm{Next}$, treatment under acidic conditions opens the anhydride units resulting in a poly(St-altMA)-block-poly(St). Table 1 lists the library of polymeric surfactants synthesized.

By varying the initial loading of St and MAn, the size of the hydrophilic and hydrophobic block was systematically varied. Two key questions were investigated to determine efficacy of the surfactant : 1) was the surfactant soluble in $\mathrm{H}_{2} \mathrm{O}$ at $1 \mathrm{wt} \%$ ?; 2) if surfactant was soluble, was it possible to prepare a stable dispersion of CNTs? A stable dispersion was defined as a small sample of CNTs ( 1-3 mg) dispersed within a $1 \mathrm{wt} \%$ solution ( $100 \mathrm{~mL}, \mathrm{H}_{2} \mathrm{O}$ ) of polymer for at least $24 \mathrm{~h}$ after sonication.

While our initial materials synthesized via ATRP/NMP (See the Supplemental Information for discussion of materials prepared) displayed a dependence on the size of the hydrophilic and hydrophobic segments to disperse CNT, the polymers prepared via RAFT were able to disperse CNT if they were soluble at $1 \mathrm{wt} \%$ in $\mathrm{H}_{2} \mathrm{O}$ regardless of the size of the hydrophilic and hydrophobic segments. While we had initially hypothesized that a strong correlation between the length of the hydrophobic poly(St) and dispersability of the CNT would exist, the ability for all water soluble polymers to disperse CNT led us to question the interactions between the CNT and the polymer.

In an effort to explore the nature of how the polymer interacts with the CNT, we utilized atomic force microscopy (AFM), Figure 1. Solutions of nanotubes with and without polymer surfactant were dispersed onto silicon surfaces by aerosol deposition. Polymer 16 from Table 1 was utilized in Figure 1A and 1B. Polymer 11 from Table 1 was utilized in Figure 1C. To prevent all of the nanotubes from being buried in a polymer layer, the solution was deposited one layer at a time and dried before the next layer was applied. Non-contact AFM was used to probe the morphology of the surface-bound nanotube/polymer hybrids. 
For dispersions of both single-walled and multi-walled nanotubes prepared with polymeric surfactants (Figure $1 \mathrm{~A}$ and $\mathrm{C}$, respectively), AFM topographs show patterns of bands along the nanotube axes that are consistent with the hypothesis that the nanotubes are wrapped by the polymer in solution and that these non-covalent composites maintain their structure when dried onto a surface. When a layer of polymeric surfactant and pristine CNTs were deposited in sequential order (Figure 1B), no similar banding patterns on the CNTs were observed, ruling out the possibility that the bands were an artifact arising from the roughness of the polymer surface supporting the CNTs. Single-walled nanotubes were used in addition to multi-walled nanotubes. Because of their narrower diameters, it was possible to distinguish individual nanotubes wrapped by polymer and to eliminate the possibility that the observed patterns were a result of nanotubes wrapping into bundles. The bands do not show a regular repetition interval, but this is consistent with previous scanning tunneling microscopy studies of P3HT wrapped on nanotubes. ${ }^{25,26}$

While dispersion tests and AFM analysis indicated that the polymeric surfactant are interacting with the CNT, we desired a more quantitative test to probe the system and looked to various fluorescence quenching and absorbance experiments.

It has been previously demonstrated that fluorescent dyes complex to the surface of the CNT, which results in a quenching of fluorescence by forming a stable ground state complex. ${ }^{27}$ We hypothesized that the addition of the polymer surfactant would interact with the CNT and separate the dye from the CNT resulting in the restoration of fluorescence, as illustrated in Figure 2. Figure 3 displays results of the proposed fluorescence quenching experiment employing Rhodamine 6G. A significant decrease in fluorescence is observed upon the addition of CNTs to the dye. However, the addition of polymeric surfactant does not increase the intensity of fluorescence from the dye. By changing the order of addition such that the CNTs and the polymeric surfactant are mixed together first followed by addition of dye, an increase in fluorescence is observed thus indicating that the interaction between the CNT and polymer inhibits interaction between the dye and CNT. Therefore, we concluded that the interaction between the fluorescent probe and the CNT appeared to be strong enough that the surfactant could not displace the probe.

Additionally, we would sometimes observe unexpected quenching without the addition of CNT when we varied the concentration of polymer surfactant in solution. These issues were observed with a wide range of fluorescent probes. The polymeric surfactants can form solution-state structures in the presence and absence of CNTs. The formation of micelle structures can lead to a false positive of quenching result. We attempted to determine the critical micelle concentration (CMC) of the samples prepared and found the $\mathrm{CMC}$ to be well below the concentration employed for dispersion experiments. In general, the average CMC for the samples prepared was below $0.5 \mathrm{mg} / \mathrm{mL}$, a range which is significantly below the typical loading level of 2.5 $\mathrm{mg} / \mathrm{mL}$ for these experiments.

To combat these issues, we employed a different probe molecule. Reichardt's dye is a solvatochromic dye that exhibits shifts in its absorbance spectra based upon the dielectric of the surrounding solvent system. ${ }^{28,29}$ By focusing upon absorbance 
measurements, we hoped to eliminate the issue of quenching caused by dye-dye interactions in micelles. Additionally, we hypothesized that the shift in the absorbance would indicate whether the dye was in a hydrophilic or hydrophobic environment, such as free in solution or interacting with the CNT or polymer.

Figure 4 displays typical absorbance measurements of various combinations of polymeric surfactant, CNTs and dye. Table 2 lists the $\lambda_{\max }$ and difference between relevant combinations of all polymer samples that displayed solubility at $1 \mathrm{wt} \%$ in $\mathrm{H}_{2} \mathrm{O}$. Figure 4 corresponds to the Polymer 11 system. As expected, shifts in the absorbance spectrum correlate to different environments of the probe molecule, where shifts to longer wavelengths indicate a more hydrophobic environment and shifts to shorter wavelengths indicate a more hydrophilic environment.

A 60:40 mixture of DMSO: $\mathrm{H}_{2} \mathrm{O}$ was chosen as the solvent system to aid in the dispersion of the CNTs and solubility of Reichardt's dye. Attempts to adequately disperse CNT in pure $\mathrm{H}_{2} \mathrm{O}$ required extremely large volumes of solution and required a larger amount of polymer. Results from initial fluorescence and absorbance experiments with pure $\mathrm{H}_{2} \mathrm{O}$ displayed identical trends as the 60:40 mixed solvent system, indicating that the change in solvent has no/minimal effect on how the polymer interacted with the CNT. The $\lambda_{\max }$ of the dye alone was $531.5 \mathrm{~nm}$. Addition of the CNT displayed little effect upon the $\lambda_{\max }$ of the dye resulting in a $\lambda_{\max }$ of 531.0. We hypothesize that because the CNT is not well dispersed, it behaves as a heterogeneous solid and does not act as solute that can interact with Reichardt's dye.

We had previously observed that the polymeric surfactant would form micellular structures and the Rhodamine 6G was located within the core of the micelle. We initially hypothesized that Reichardt's dye would behave similiarly, however this was not observed. In all cases, addition of the polymeric surfactant shifted the $\lambda_{\max }$ to a shorter wavelength indicating a more hydrophilic environment. To determine how Reichardt's dye was interacting with the polymeric surfactant, we employed ${ }^{1} \mathrm{H}$ NMR and ${ }^{1} \mathrm{H}$ NMR NOESY experiments to probe interactions between the species, as shown in Figure 5. Previous work with Reichardt's dye was able to determine the location of the dye within polymeric species. ${ }^{30}$ Figure $5 \mathrm{~A}$ displays a clear shift in the aromatic region upon the addition of Reichardt's dye. Additionally, in the ${ }^{1} \mathrm{H}$ NOESY NMR spectra (Figure 5B), there is significant correlation between the aromatic region corresponding to Reichardt's dye and the methylene units of the polymer backbone, assigned as peaks $\mathrm{G}$ in Figure 5. The bands present in the ${ }^{1} \mathrm{H}$ NOESY spectra are caused by residual $\mathrm{D}_{2} \mathrm{O}$, d6-DMSO and triethylamine. An equimolar amount of triethylamine relative to carboxylic acid functional groups is added to deprotonate and ionize that functional group. This aids in water solubility, and we hypothesize that the ionized acid groups aid in the wrapping of the polymer around the CNT, especially in the mixed solvent system. It has been well documented that the local microstructure of the solute-solvent system can create dipole moments that will shift the $\lambda_{\max }$ of Reichardt's dye. ${ }^{28,29}$ In particular, the presence of salts and ionic species can cause significant shifts in the $\lambda_{\max }{ }^{28,29}$ The ${ }^{1} \mathrm{H}$ NOESY correlation and the large shift in $\lambda_{\max }$ indicates that Reichardt's dyes is located near the ionized maleic acid functional groups. 
While we observed that the order of addition influenced fluorescence experiments, that trend was not observed when we employed Reichardt's dye. We hypothesize that the extended $\pi$ orbital network of Reichardt's dye decreases the strength of $\pi-\pi$ stacking between the CNT and Reichardt's dye which allows for displacement upon addition of the polymer. Additionally, although Reichardt's dye is fully conjugated, the torsional interactions between adjacent phenyl rings disrupts the planarity of the molecule and decreases the potential interaction points between the dye and the CNT. Whereas, Rhodamine 6G can achieve a more planar conformation resulting in more interaction between the dye and the CNT. ${ }^{28,29}$ Regardless of the order of addition, upon the combination of polymer, CNT and Reichardt's dye, the $\lambda_{\max }$ again shifted to shorter wavelengths, indicating a more polar environment. A larger shift was observed as the size of the hydrophobic block was increased (while holding the hydrophilic segment constant). We hypothesize that in polymers with smaller hydrophobic segments, the polymer organizes to allow for the styrene units in the hydrophilic segment to stabilize the CNT dispersion. This excludes Reichardt's dye from the polymer backbone and away from the ionic maleic acid functional groups. As the hydrophobic segment increases, the hydrophobic styrene block interacts with the CNT which provides the hydrophilic segment the ability to maintain its free volume. This allows Reichardt's dye to maintain its interaction with the maleic acid functional groups, resulting in a shift to shorter wavelengths. Furthermore, the increased stabilization of the CNT within the solution allows it to behave as a solute and affect the dipole moment and microenvironment of the solution again resulting in a more polar environment. ${ }^{29}$ To probe this concept of orientation within the hydrophilic segment, we synthesized a polymer with only an alternating styrene-maleic acid segment (Polymer 1, Table 1). Polymer 1 was able to disperse CNT's and displayed similar trends in $\lambda_{\max }$ shifts to samples that contained a defined hydrophobic segment. While we had initially hypothesized that a strong correlation between the length of the hydrophobic poly(St) and dispersability of the CNT would exist, we determined that styrene units within the hydrophilic block can provide an interaction to adequately disperse the CNT.

\section{Conclusions}

A library of polymeric amphiphiles was prepared based on a one-pot methodology using reversible addition fragmentation chain transfer (RAFT) polymerization. These surfactants where then employed to disperse carbon nanotubes (CNTs) within in aqueous media and solutions of $\mathrm{H}_{2} \mathrm{O}$ and DMSO. All materials that were soluble in $\mathrm{H}_{2} \mathrm{O}$ were able to prepare dispersions of CNTs. Atomic force microscopy (AFM) indicated that the polymer engages the CNT through a non-uniform wrapping mechanism. Multiple optical probes, including Rhodamine 6G and Reichardt's dye, were utilized in both absorption and emission analysis to further probe the interaction between the polymer surfactant and the CNT in solution-state. In all cases, the styrene units along the polymer backbone in the hydrophobic block or within the alternating styrene/maleic acid segment are able to organize to allow $\pi-\pi$ stacking with the CNT. 


\section{Acknowledgements}

Authors would like to acknowledge Kevin Dunham for his help with NMR analysis in particular the 1D and NOESY experiments. We also acknowledge Dr. Greg O'Bryan for helpful discussion and for supplying CNTs. PJC acknowledges the donors of The American Chemical Society Petroleum Research Fund and the National Science Foundation under CHE - 1213331 for partial support of this research.

\section{References}

1. Popov, V. N. Materials Science and Engineering (R) 2004, 43, 61-102.

2. Xie, X.-L.; May, Y.-W.; Zhou, X. P. Materials Science and Engineering (R) 2005, 49, 89-112.

3. O'Connell, M. J.; Boul, P.; Ericson, L. M.; Huffman, C.; Wang, Y.; Haroz, E.; Kuper, C.; Tour, J.; Ausman, K. D.; Smalley, R. E. Chemical Physical Letters 2001, 342, 265-271.

4. Wang, H. Current Opinion in Colloid \& Interface Science 2009, 14, 364-371.

5. Vaisman, L.; Wagner, H. D.; Marom, G. Advances in Colloid and Interface Science 2006, 128-130, 37-46.

6. Wang, J.-S.; Matyjaszewski, K. Journal of the American Chemical Society 1995, $117,5614-5615$.

7. Patten, T. E.; Matyjaszewski, K. Accounts of Chemical Research 1999, 32, 895903.

8. Moad, G.; Rizzardo, E.; Thang, S. H. Accounts of Chemical Research 2008, 41, 1133-1142.

9. Hawker, C. J.; Bosman, A. W.; Harth, E. Chemical Reviews 2001, 101, 36613688.

10. Braunecker, W. A.; Matyjaszewski, K. Progress in Polymer Science 2007, 32, 93146.

11. Matyjaszewski, K.; Tsarevsky, N. V. Nature Chemistry 2009, 1, 276-288.

12. Cui, H.; Chen, Z.; Wooley, K. L.; Pochan, D. J. Macromolecules 2006, 39, 65996607.

13. Dire, C.; Charleux, B.; Magnet, S.; Couvreur Macromolecules 2007, 40, 18971903.

14. Li, Y.; Lokitz, B. S.; McCormick, C. L. Macromolecules 2006, 39, 81-89.

15. Chen, Z.; Cui, H.; Hales, K.; Li, Z.; Qi, K.; Pochan, D. J.; Wooley, K. L. Journal of the American Chemical Society 2005, 127, 8592-8593.

16. Thurmond, K. B.; Kowalewski, T.; Wooley, K. L. Journal of the American Chemical Society 1996, 118, 7239-7240.

17. Huang, H.; Kowalewski, T.; Remsen, E. E.; Gertzmann, R.; Wooley, K. L. Journal of the American Chemical Society 1997, 119, 11653-11659.

18. Colombani, O.; Ruppel, M.; Schubert, F.; Zettl, H.; Pergushov, D. V.; Muller, A. H. E. Macromolecules 2007, 40, 4338-4350.

19. Li, Z.; Chen, Z.; Cui, H.; Hales, K.; Wooley, K. L.; Pochan, D. J. Langmuir 2007, 23, 4689-4694. 
20. Jacquin, M.; Muller, P.; Cottet, H.; Crooks, R.; Theodoly, O. Langmuir 2007, 23, 9939-9948.

21. Bapat, A. P.; Ray, J. G.; Savin, D. A.; Hoff, E. A.; Patton, D. L.; Sumerlin, B. S. Polymer Chemistry 2012, 3, 3112-3120.

22. Wang, R.; McCormick, C. L.; Lowe, A. B. Macromolecules 2005, 38.

23. Odian, G. Principles of Polymerization; John Wiley \& Sons: Hoboken, New Jersey, 2004.

24. Benoit, D.; Hawker, C. J.; Huang, E. E.; Lin, Z.; Russell, T. P. Macromolecules 2000, 33, 1505-1507.

25. Giulianini, M.; Waclawik, E. R.; Bell, J. M.; De Crescenzi, M.; Castrucci, P.; Scarselli, M.; Motta, N. Appl. Phys. Lett. 2009, 95, 013304-1 - 013304-3.

26. Giulianini, M.; Waclawik, E. R.; Bell, J. M.; Scarselli, M.; Castrucci, P.; De Crescenzi, M.; Motta, N. Appl. Phys. Lett. 2009, 95, 143116-1 - 143116-3.

27. Ahmad, A.; Kurkina, T.; Kern, K.; Balasubramanian, K. ChemPhysChem 2009, 10, 2251-2255.

28. Reichardt, C. Chem Rev 1994, 94, 2319-2358.

29. Reichardt, C.; Welton, T. Solvents and solvent effects in organic chemistry; Wiley-VCH, 2011.

30. Morgan, M. T.; Carnahan, M. A.; Immoos, C. E.; Riberio, A. A.; Finkelstein, S.; Lee, S. J.; Grinstaff, M. W. J. Am. Chem. Soc. 2003, 125, 15485-15489. 
Table 1. Summary of reaction conditions, materials prepared and qualitative dispersion tests.

\begin{tabular}{|c|c|c|c|c|c|c|c|c|c|c|c|}
\hline \multirow[t]{2}{*}{ Sample } & \multirow[t]{2}{*}{ Ratios } & \multirow{2}{*}{$\begin{array}{l}\text { Time } \\
(\min )\end{array}$} & \multirow[t]{2}{*}{$\%$ Conversion $^{a}$} & \multicolumn{2}{|c|}{$\mathrm{DP}$} & \multicolumn{2}{|c|}{ Mol\% } & \multicolumn{2}{|c|}{$\mathrm{M}_{\mathrm{n}}(\mathrm{g} / \mathrm{mol})$} & \multirow{2}{*}{$\begin{array}{c}\mathrm{H}_{2} \mathrm{O} \text { soluble } \\
@ 1 \%\end{array}$} & \multirow{2}{*}{$\begin{array}{c}\text { Disperse } \\
\text { CNT }\end{array}$} \\
\hline & & & & $1^{\text {st }}$ block & $2^{\text {nd }}$ block & $1^{\text {st }}$ block & $2^{\text {nd }}$ block & NMR & GPC (PDI) & & \\
\hline 1 & $25: 65: 0.2: 1$ & 120 & 32 & 42 & 0 & 100 & 0 & 4,200 & $5,400(1.60)$ & $\mathrm{Y}$ & $\mathrm{Y}$ \\
\hline $2^{c}$ & $25: 65: 1: 1$ & 1200 & 57 & 50 & 10 & 83 & 17 & 6,100 & $7,000(1.67)$ & $\mathrm{Y}$ & $\mathrm{Y}$ \\
\hline 3 & $25: 65: 0.2: 1$ & 1380 & 73 & 50 & 22 & 69 & 31 & 7,300 & $7,800(1.47)$ & Y & Y \\
\hline 4 & $25: 60: 1: 1$ & 1440 & 95 & 50 & 32 & 60 & 40 & 8,400 & $8,700(1.54)$ & $\mathrm{Y}$ & Y \\
\hline $5^{a}$ & $25: 100: 1: 1$ & 1320 & 84 & 50 & 59 & 45 & 55 & 11,200 & $12,700(1.27)$ & $\mathrm{Y}$ & Y \\
\hline $6^{e}$ & $25: 200: 0.2: 1$ & 960 & 48 & 50 & 71 & 41 & 60 & 12,500 & $16,800(1.26)$ & $\mathrm{N}$ & n.a. \\
\hline $7^{d}$ & $25: 300: 1: 1$ & 1320 & 54 & 50 & 137 & 26 & 74 & 19,300 & $20,400(1.20)$ & $\mathrm{N}$ & n.a. \\
\hline 8 & $50: 75: 0.5: 1$ & 1080 & 86 & 100 & 14 & 87 & 13 & 11,600 & $9,500(1.36)$ & $\bar{Y}$ & $\mathrm{Y}$ \\
\hline 9 & $50: 90: 0.5: 1$ & 1080 & 86 & 100 & 24 & 78 & 22 & 12,900 & $9,300(1.32)$ & Y & Y \\
\hline 10 & $50: 120: 0.5: 1$ & 1080 & 76 & 100 & 41 & 70 & 30 & 14,400 & $16,100(1.32)$ & Y & Y \\
\hline 11 & $50: 150: 0.5: 1$ & 1080 & 71 & 100 & 56 & 63 & 37 & 15,900 & $17,300(1.32)$ & Y & $Y$ \\
\hline 12 & $50: 180: 0.8: 1$ & 1080 & 75 & 100 & 85 & 53 & 47 & 19,000 & $20,000(1.22)$ & $\mathrm{N}$ & n.a. \\
\hline 13 & $75: 150: 0.3: 1$ & 90 & 53 & 150 & 5 & 97 & 3 & 15,600 & $14,800(1.45)$ & $\mathrm{Y}$ & $\mathrm{Y}$ \\
\hline 14 & $75: 150: 0.3: 1$ & 300 & 58 & 150 & 12 & 92 & 8 & 16,400 & $10,800(1.56)$ & Y & Y \\
\hline 15 & $75: 150: 0.3: 1$ & 1080 & 78 & 150 & 41 & 78 & 22 & 19,400 & $17,300(1.35)$ & Y & Y \\
\hline $16^{e}$ & $75: 200: 0.2: 1$ & 960 & 68 & 150 & 61 & 71 & 30 & 21,500 & $25,300(1.18)$ & Y & Y \\
\hline 17 & $75: 200: 1: 1$ & 1260 & 81 & 150 & 87 & 63 & 34 & 24,200 & $19,500(1.24)$ & Y & Y \\
\hline $18^{d}$ & $75: 300: 1: 1$ & 1320 & 65 & 150 & 120 & 55 & 45 & 27,700 & $20,300(1.25)$ & Y & Y \\
\hline $19^{t}$ & $75: 400: 1: 1$ & 2880 & 96 & 150 & 310 & 32 & 68 & 47,500 & $17,800(1.19)$ & $\mathrm{N}$ & n.a. \\
\hline
\end{tabular}

Conditions : ${ }^{a}$ Conversion based upon ${ }^{1} \mathrm{H}$ NMR analysis. ${ }^{b} \mathrm{M}_{\mathrm{n}}$ based upon linear poly(St) standards. All polymerizations run at $65{ }^{\circ} \mathrm{C}$ and $40 \%$ solvent, unless otherwise noted. ${ }^{c} 60{ }^{\circ} \mathrm{C}$; $37 \%$ solvent; ${ }^{d} 60{ }^{\circ} \mathrm{C} ; 47 \%$ solvent; ${ }^{e} 70{ }^{\circ} \mathrm{C} ; 37 \%$ solvent; ${ }^{f} 45 \%$ solvent. 
Table 2. Summary of UV/Vis absorbance experiments of Reichardt's dye, polymeric surfactant and CNT.

\begin{tabular}{|c|c|c|c|c|c|c|c|c|c|c|c|c|c|c|c|c|}
\hline Entry & Sample $^{a}$ & 1 & 2 & 3 & 4 & 5 & 8 & 9 & 10 & 11 & 13 & 14 & 15 & 16 & 17 & 18 \\
\hline (A) & $\begin{array}{c}\text { DYE + } \\
\text { Polymer }\end{array}$ & 520.8 & 522.47 & 520.2 & 522.80 & 511.40 & 522.27 & 523.72 & 522.07 & 520.73 & 522.27 & 521.93 & 523.93 & 520.35 & 522.07 & 521.47 \\
\hline & $\begin{array}{l}\text { Polymer } \\
+ \text { CNT }\end{array}$ & 519.2 & 520.72 & 518.33 & 520.60 & 510.00 & 522.80 & 521.57 & 520.53 & 516.73 & 522.20 & 521.07 & 522.20 & 517.93 & 518.13 & 518.73 \\
\hline (C) & $\begin{array}{l}\triangle \mathrm{DYE}^{b} \\
\text { and }(\mathrm{A})\end{array}$ & -10.95 & -9.23 & -11.72 & -8.40 & -20.50 & -9.43 & -5.47 & -9.13 & -10.97 & -9.43 & -9.82 & -7.97 & -11.35 & -9.63 & -10.33 \\
\hline (D) & $\begin{array}{c}\Delta(\mathrm{A}) \\
\text { and }(\mathrm{B})\end{array}$ & -1.6 & -1.74 & -1.87 & -2.2 & -0.70 & 0.53 & -2.16 & -1.54 & -4 & -0.07 & -0.87 & -1.73 & -2.42 & -3.94 & -2.74 \\
\hline
\end{tabular}

Conditions : ${ }^{a}$ [DYE] - $218.9 \mu \mathrm{M}$; [Polymer] - $2.5 \mathrm{mg} / \mathrm{mL}$; CNT - $10 \mu \mathrm{g} / \mathrm{mL} .{ }^{b} \lambda_{\max }{ }^{\text {Dye }}-531.5\left(\lambda_{\max }\right.$ Reichardt's dye in 60:40 DMSO:H 
Scheme 1. Synthetic route for preparation of polymeric amphiphiles

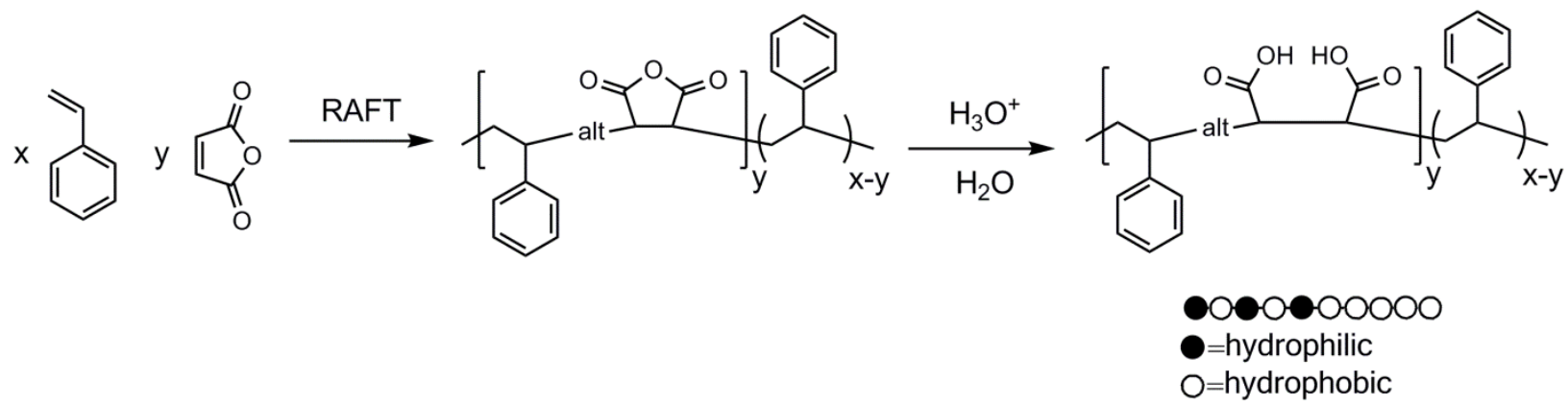



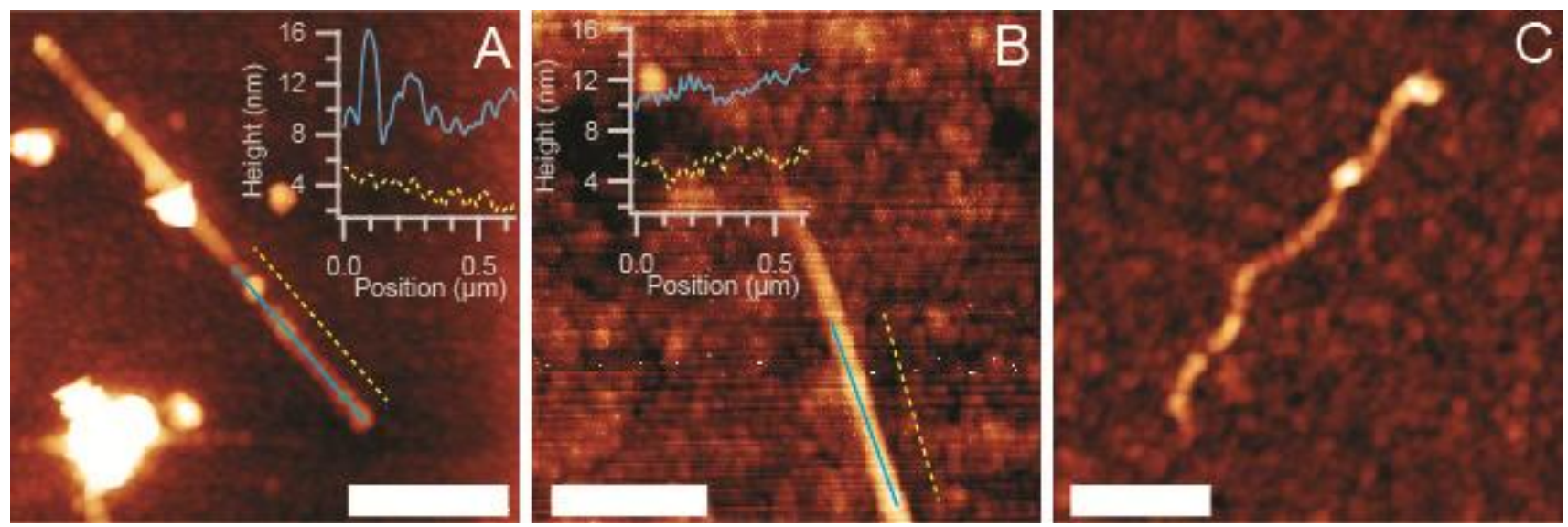

Figure 1. AFM images of CNTs that were deposited onto silicon substrates from polymeric surfactant solutions (A - single walled CNT; C - multi walled CNT) and on top of (B) dried polymeric surfactants. Scale bar - $500 \mu \mathrm{m}$. Polymer 16 from Table 1 was employed in tiles A and B. Polymer 11 from Table 1 was employed in tile C. 


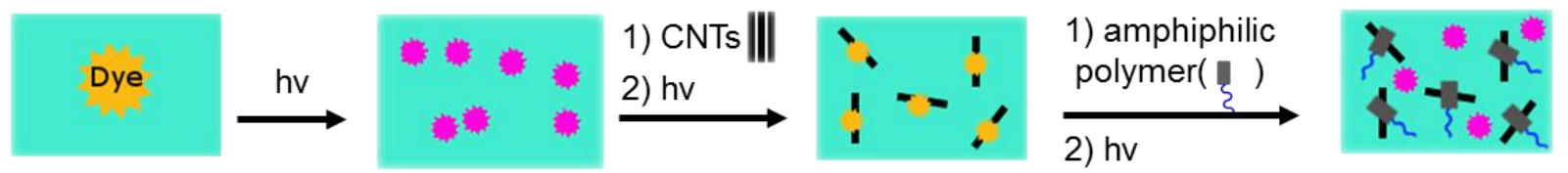

Figure 2. Proposed fluorescence quenching experiment 


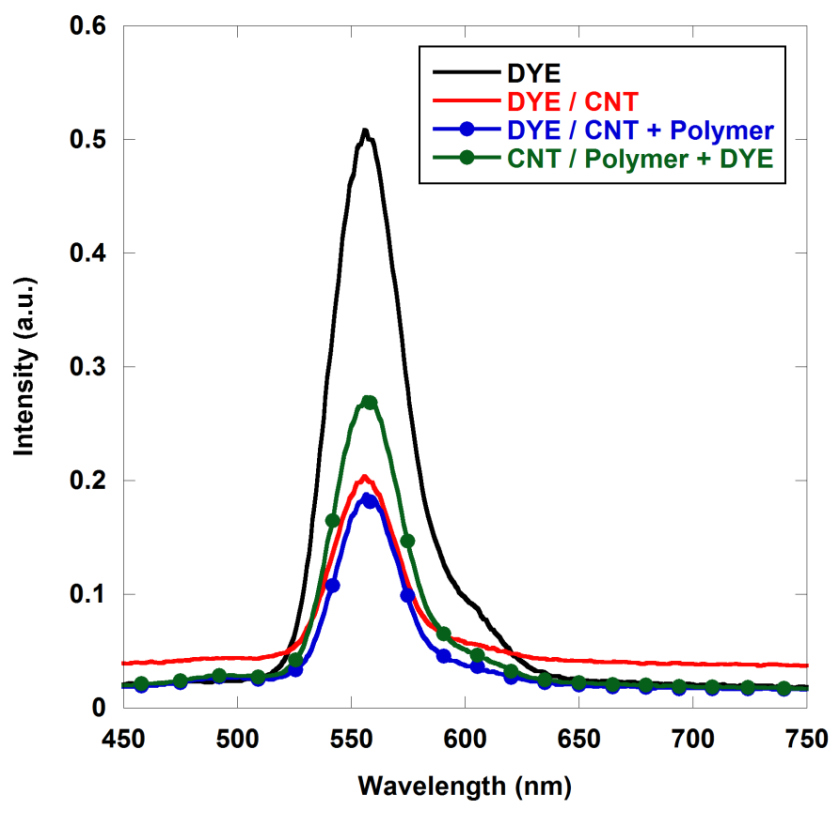

Figure 3. Emission spectra of Rhodamine $6 \mathrm{G}(2.5 \mu \mathrm{M})$ in water, with CNTs $(16 \mu \mathrm{g} / \mathrm{mL})$, and with CNTs and polymer $(0.220 \mathrm{mM})$ at an excitation wavelength of $500 \mathrm{~nm}$. 


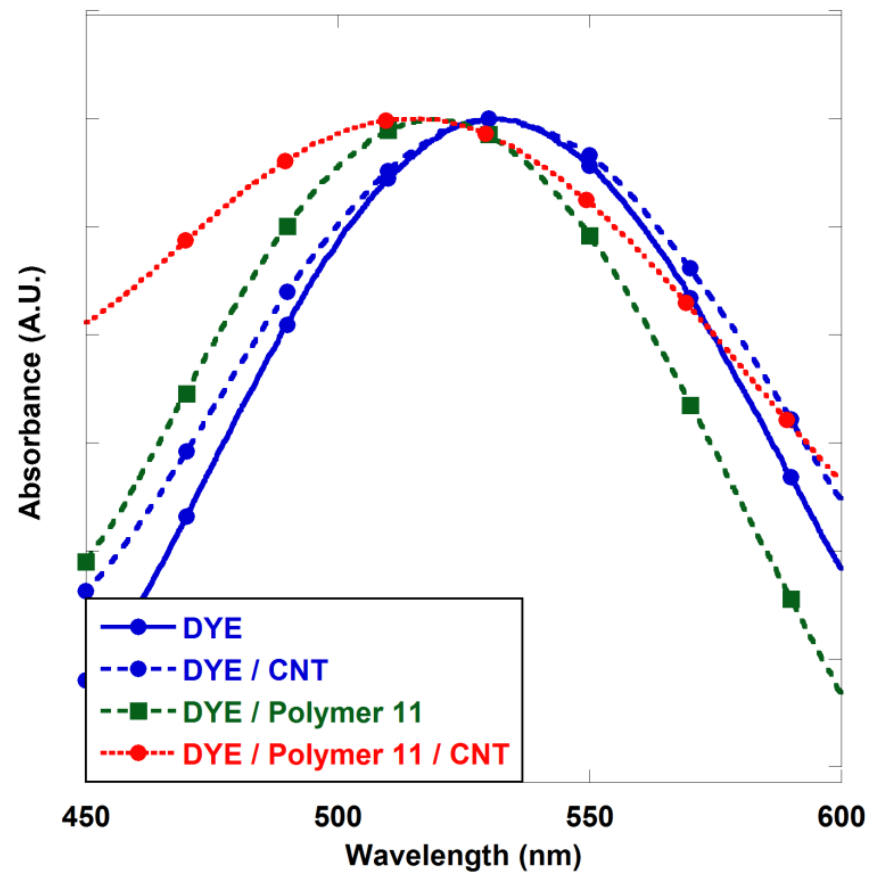

Figure 4. Absorbance spectra of Reichardt's dye $(219 \mu \mathrm{M})$ in 60:40 DMSO: $\mathrm{H}_{2} \mathrm{O}$, with CNTs $(10 \mu \mathrm{g} / \mathrm{mL})$ and Polymer $11(2.5 \mathrm{mg} / \mathrm{mL})$. 

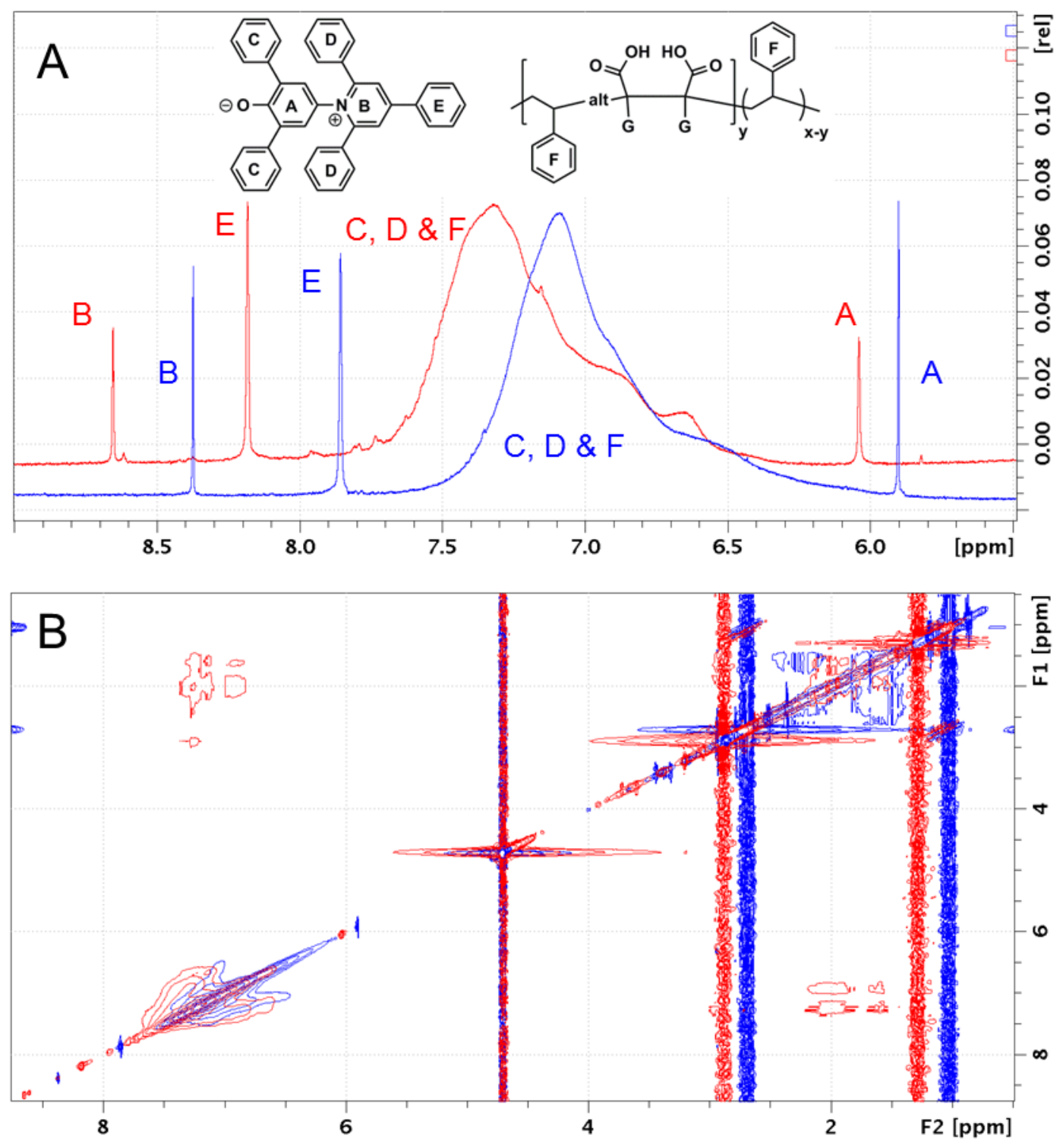

Figure 5. NMR analysis of Polymer 2 without (blue) and with (red) Reichardt's dye in 60:40 d6-DMSO: $\mathrm{D}_{2} \mathrm{O}$. A) Overlay of ${ }^{1} \mathrm{H}$ NMR spectra; B) ${ }^{1} \mathrm{H}$ NOESY NMR spectra. 